\title{
The Effect of Alternative Assessment on the Attitudes and Achievement in Mathematics of Female Pre-Service Teachers in Ghana
}

\author{
ESHUN, B. A. \\ Department of Science Education, \\ University of Cape Coast \\ Cape Coast, Ghana \\ $\&$ \\ ABLEDU, G. K. \\ Faculty of Science Education, \\ University of Cape Coast \\ Cape Coast, Ghana
}

\begin{abstract}
This paper examines the effect of exposing one of two groups of preservice female teachers to alternate forms of assessment. Both groups were first year students in a teacher training college and received 8 weeks of normal instruction in mathematics content and traditional assessment by the same teacher. The students were interviewed on their attitudes towards mathematics before and after instruction. In addition, the students took two pretests and corresponding posttests. The external achievement tests were similar to the 1997 Mathematics Paper of the Senior Secondary School Certificate Examination (SSSCE) and the internal achievement tests were based on the content of instruction. The results of the study showed significant improvement in both the internal and external achievement of the experimental group, but only significant improvement in the internal achievement of the control group. Also, the experimental group achieved higher gains on both achievement tests than the control group. Students in the experimental group exhibited greater positive attitudinal changes and expressed the benefits they derived from the alternative assessment activities in their journals and portfolios. Suggestions for intervention programmes to improve female pre-service teachers' attitudes, achievement and participation in mathematics are discussed.
\end{abstract}

\section{Introduction}

Pre-service teachers are admitted directly into Teacher Training Colleges in Ghana based on their performance in the Senior Secondary School Certificate Examination (SSSCE). All pre-service teachers take mathematics content for the first two years of the three-year teacher education programme. Studies on achievement of secondary school students in 
The Effect of Alternative Assessment on the Attitudes and Achievement in Mathematics of Female Pre-Service Teachers in Ghana ESHUN, B. A. \& ABLEDU, G. K.

Ghana show a low achievement in mathematics and females' achievement is lower than that of males (Eshun, in press). The lower achievement of females in mathematics is reported in studies in other countries (Carpenter, Lindquist, Matthews and Silver, 1983; APU, 1985; Maqsud and Khalique, 1991; Randhawa, 1991). The achievement of pre-service teachers in mathematics is far lower than that of most secondary school students in Ghana. In 1998, about half of the pre-service teachers scored less than 17 per cent in basic mathematics which were the contents of their end of yearone examination, designated Part I Examination (University of Cape Coast Institute of Education, 1998).

Ghana embarked on a comprehensive education reform in 1987 and teachers of high calibre and professional competence are needed in adequate numbers (Ghana Ministry of Education, 1993) to implement it and achieve the expected goals of functional literacy and numeracy for all pupils. But the results of Criterion Reference Tests (CRT) conducted between 1992 and 1995 indicate that only 1.8 per cent of primary grade 6 pupils have mastered the items in mathematics and the mean performance is less than 30 per cent (Ghana Ministry of Education, 1995).

All pre-service teachers in Ghana are trained to teach in primary grades 1 through 6 . The very poor grades in mathematics of pre-service teachers in the SSSCE and their continued poor performance in the 3-Year Post Secondary Teacher Training College Examination in Basic Mathematics negatively impact on their teaching of mathematics in the primary schools and are a contributing factor in pupils' dismal performance in the CRT. Thus it is crucial that pre-service teachers' performance in mathematics be improved.

As part of the Educational Reform of 1987 continuous assessment of students (throughout the school year) and external examination are used to assess students' work for final certification (Ghana Ministry of Education, 1987) at all levels of education. Host and Bloomfield (1975) recommended the continuous assessment model as a better system of assessment than just a 2- or 3-hour examination. Continuous assessment is therefore expected to improve, and make more reliable, teachers' assessment of students' work. But in Ghana the emphasis on traditional forms of assessment such as quizzes and tests in continuous assessment make it less effective in improving students' learning and thereby their performance.

Alternative assessment is a generic term referring to the new forms of assessment (Winzer, 1992) other than traditional forms of assessment. The main goal of alternative assessment is to "gather evidence about how students are approaching, processing, and completing "real-life" tasks in a particular domain" (Garcia and Pearson, 1994). Alternative assessment may include interview with students, journal writing, students' development of portfolios of their work and writing of reflections on it. Also, students are encouraged to engage in small-group cooperative learning and be assessed individually and jointly. Thus in the alternative assessment process, a 
student gets the opportunity to be responsible for selecting products of his/her work on which to be assessed and to reflect on his/her learning experience, pointing out what he/she understands and factors that contribute to his/her lack of understanding (Huerta-Marcias, 1995).

A major advantage of alternative assessment as a tool for assessing students is that it empowers them to become partners and decision makers in their learning (Smolen et al., 1995). Lee (1997) found that the real value of alternative assessment is an information source for teachers and a learning tool for the students. Viaskamp (1995) found that alternative assessment processes engage students to become active in learning through reflection and judgment of their own learning.

It is important to provide pre-service teachers with a form of assessment that enables them to identify their strengths and weaknesses in learning mathematics in order to improve their performance. In the process they will acquire a system of assessment that they in turn can use with their pupils in the primary school. Alternative assessment is very much new in Ghana. This study in alternative assessment and especially with female pre-service teachers is therefore intended to:

i. Examine the effect of alternative assessment on female pre-service teachers' performance in mathematics.

ii. Describe the effect of alternative assessment on female pre-service teachers' attitudes towards mathematics.

iii. Examine female pre-service teachers' perceptions about alternative assessment as a tool for demonstrating their progress in mathematics

\section{Method}

The population for the study was the 1998/99 first year pre-service female teachers in the Central Region of Ghana. The sample consisted of two intact classes of students in OLA Training College in Cape Coast. Tests similar to the SSSCE Mathematics Paper 1 for 1997 was constructed by the researchers and referred to as external achievement tests. Also, tests based on the mathematics content to be covered during the study was constructed and referred to as internal achievement tests. A pretest of the external achievement test was administered to both classes of students. The class with the higher mean score was designated as the control group and the one with the lower mean score as the experimental group. The two groups were also given a pretest of the internal achievement test. Both groups were then given instruction for eight weeks based on the Post Secondary Teacher Training College Mathematics Syllabus for Year One by one of the researchers and given traditional assessment during the period of the study. In addition the experimental group was given a treatment consisting of the various forms of alternative assessment. At the end of the study, the groups were given posttests on the external and internal achievement tests and their performances analysed and compared. 
Using the pretest results, three ability strata were defined. These were the top $25 \%$ as the high ability group, the middle $50 \%$ as the average ability group and the bottom $25 \%$ as the low ability group. A random selection of three, four and three students from the three ability groups respectively was made for each of the experimental and control groups. These students were interviewed before and after the study to examine the changes in their attitudes towards mathematics and in their knowledge about mathematics concepts on the internal pretest items. Guidelines were given at the beginning of the study to the experimental group to enable them work successfully in small-group cooperative learning settings, write suitable reflections, keep journals and develop portfolios.

\section{Results}

\section{Pretests and Posttests}

Table 1 shows the mean scores on the two pretests and two posttests given to the experimental and the control groups. The total scores for the internal and external achievement tests were 15 and 20 respectively. The t-test values for the difference between the mean scores for the two groups on the internal and external pretests were 0.2 and 1.6 respectively, which are not significant. Thus there was no significant difference between the mathematics achievements of the two groups on both pretests. The groups were therefore equivalent at the beginning of the study. The t-test values for the difference between the mean scores on the pretest and posttest for the internal and external achievement tests were 6.9 and 3.4 respectively for the experimental group and 4.7 and 1.3 respectively for the control group. Thus there was significant improvement in the achievement of the experimental group on both the internal and external tests. While there was significant improvement in the achievement of the control group on the internal tests, there was no significant improvement in their achievement on the external tests. 
Table 1. Mean Scores On Pretests And Posttests Achievement Measures

\begin{tabular}{|c|c|c|c|c|}
\hline Group & $\begin{array}{l}\text { 芯 } \\
\stackrel{0}{0} \\
\dot{0}\end{array}$ & 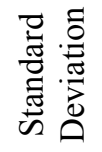 & 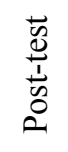 & 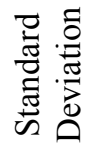 \\
\hline \multicolumn{5}{|l|}{ Internal Achievement } \\
\hline Control Group & 4.4 & 2.7 & 7.4 & 3.1 \\
\hline Experimental Group & 4.3 & 8.6 & 8.6 & 2.6 \\
\hline \multicolumn{5}{|l|}{ External Achievement } \\
\hline Control Group* & 4.0 & 2.9 & 4.9 & 3.4 \\
\hline Experimental Group** & 3.0 & 2.6 & 5.0 & 2.5 \\
\hline
\end{tabular}

Table 2 Mean Scores of Students on Internal Pretest and Posttest by Type of Group And Ability Level

\begin{tabular}{lccc}
\hline & \multicolumn{2}{c}{ Group } & \multirow{2}{*}{ t-value } \\
\hline Low Ability & & & \\
Pretest & 1.6 & 1.4 & \\
Posttest & 7.3 & 4.6 & \multirow{2}{*}{$2.84^{*}$} \\
Gain & 5.7 & 3.2 & \\
Average Ability & & & \\
Pretest & 3.6 & 4.3 & \\
Posttest & 8.2 & 8.0 & \multirow{2}{*}{ Control } \\
Gain & 4.6 & 3.7 & \\
High Ability & & & \\
Pretest & 7.6 & 8.0 & \\
Posttest & 10.5 & 10.0 & \\
Gain & 2.9 & 2.0 & 1.87 \\
\hline
\end{tabular}

$* \mathrm{p}<0.05$

Table 2 shows the mean scores for students at three ability levels, low, average and high for each of the experimental and control groups on the internal pretest and posttest. The results show that there was significant difference between the mean gain scores of the low ability groups but no significant difference between the average and high ability groups. However, the low ability students in the experimental group achieved significantly higher than their counterparts in the control group. Also, Table 2 shows that all the ability groups in the experimental group achieved higher than their counterparts in the control group.

\section{Journals and Portfolios}

The experimental group students' reflections in their journals and portfolios indicate that $85 \%$ of them felt they were not good at mathematics and $90 \%$ of them did not like mathematics when they were in the Senior Secondary 
The Effect of Alternative Assessment on the Attitudes and Achievement in Mathematics of Female Pre-Service Teachers in Ghana ESHUN, B. A. \& ABLEDU, G. K.

School (SSS). About $85 \%$ mentioned teachers as factors that contributed to their failure in or dislike for mathematics. The following student's reflection expressed a typical feeling:

I do not actually like maths because it involves lot of calculations and thinking. The teacher's laziness made me hate maths since he did not teach us well, and was sometimes not present in class. (Ace)

As many as $83 \%$ of the students documented that doing homework, class tests and out-of-class activities individually and in small-group cooperative learning settings helped them to understand mathematics and to be more predisposed to solving mathematics problems. Two students' reflections were typical:

Learning in group also helped a lot because what you don't understand is what someone understands very well. So we share ideas. Working individually also helped me to know my weak points to be able to bring it out during group discussion. (Cas)

When we work group test, that one becomes effective because one person will bring an idea, the other too will bring her's and put together and produce something good. In group work people learn new ideas and others tend to benefit. (Ita)

Comparing their attitudes towards mathematics and their achievement in mathematics at the training college and earlier at the SSS, $60 \%$ documented that there has been a positive change in their attitude towards mathematics and $71 \%$ had experienced an improvement in their mathematics achievement. As many as $84 \%$ attributed these changes to the extra group activities and the writing of journals and the developing of portfolios. One student's reflection sums up the feelings of many others:

I have improved my performance in maths very well and I have interest in it than at first. My attitude towards maths has also improved because I learn and understand it in group discussion. (Bel)

Not all the students were positive about having to work in small groups. While $62 \%$ wrote that it enhanced their learning of mathematics, $38 \%$ of them thought otherwise.

Doing homework and tests in a group is very slow and often very disheartening. More often than not, a person is very uncooperative. Others pass insulting comments. (Her)

Doing homework in groups at times discourages me. This is because your opinion may differ from someone else's own and both of you cannot come to a compromise. If homework is done individually it makes you write what you know without any disagreement anywhere." (Red)

There was an improvement in the achievement of students as well as a positive change in their attitudes towards mathematics. One student's reflection shows how she was motivated to do extra practice on her own. 
There has been an improvement since I came to this college. My attitude towards mathematics is that I am not afraid of mathematics any more as I used to. It has encouraged me so much that I use 30 minutes to work mathematics always. (Mae)

\section{Interviews}

Interviews with students revealed several misconceptions students had before the start of the study. Students interpreted the relation $\frac{1}{2}=\frac{2}{4}=\frac{3}{6}$ as increasing the numerator and denominator of $\frac{1}{2}$ by 1 and 2 respectively to get $\frac{2}{4}$ rather than multiplying both numerator and denominator of by 2 . Similarly, they explained that the numerator and denominator of $\frac{1}{2}$ was increased by 2 and 4 respectively to get $\frac{3}{6}$ rather than multiplying both by 3. Also, some students could not change mixed numbers to improper fractions correctly. One student could not see anything wrong with her explanation for the conversion, $2 \frac{4}{15}+3 \frac{1}{3}=\frac{8}{15}+\frac{3}{8}$. To her, the whole number must be multiplied by the numerator and not the denominator, because the product is a numerator.

\section{Discussion}

The findings of the study provided multiple indices for gauging students' progress (Huerta-Marcias, 1995) and support many of the positive benefits of alternative assessment. The significant improvement in the performance of only the experimental group on the external tests indicate that the alternative assessment activities significantly increased the students' ability to use problem solving approaches in new situations. The significantly higher performance by the low ability students of the experimental group than their counterparts in the control group on the internal tests indicates that female students with lower achievement in mathematics benefit greatly when exposed to alternative assessment. In particular, it is conjectured that the small-group cooperative learning settings addressed the low ability students' need for individual attention and motivation which were provided by their more able peers.

Students' reflections in their journals and portfolios provided evidence of positive change in their attitudes towards and learning of mathematics (LeMahieu et al, 1995). In particular, the students in the experimental group had the opportunity to organise and initiate their individual and group learning activity. This in turn contributed to their higher achievement which Garcia and Pearson (1994) and Johnson and Johnson (1978) see as the main goal of alternative assessment. 
The significant improvement in the performance of the students in the experimental group indicates that if teacher educators in training college were to adopt the alternative assessment form, female students would improve their performance in the first year and some of them will be encouraged to offer elective mathematics in their second and final years. The interviews with the students uncovered their misconceptions of fractions and analysis of students' mistakes revealed what and why they failed to understand. This supports the findings of Erlwanger (1973), Newman (1977) and Alison and Mammino (1987).

The control group's higher performance on the pretests did not give them any advantage in the study. Rather the experimental group surpassed the control group. This indicates that the students exposed to the alternative assessment retained significantly more mathematics concepts and skills taught in the study than their counterparts who were exposed to only traditional assessment. The study suggests that alternative assessment processes can be used to cause female pre-service teachers to integrate mathematics content conceptually.

The issue of the relative practicality of alternative assessment, in terms of time consumption, has been raised by many authors (Gipps, 1994; Linn and Burton, 1994). The study findings indicate that alternative assessment is not more time consuming than traditional assessment on the part of these students. The students in both groups had the same available time as they lived in dormitories on the school campus. The study suggests that students can cope with the time demands of alternative assessment.

Alternative assessment is a new concept in Ghana, and for its effective implementation, teachers will need in-service training in it. The study suggests that such training is worthwhile since teachers will have the means to bring about higher achievement in mathematics and positive attitudinal changes in female pre-service teachers. There is the need for further research to investigate the attitudes of teachers themselves towards the use of alternative assessment processes. Also, further research is needed to investigate whether there are gender differences in the benefits of alternative assessment in mathematics.

\section{References}

Alison, L. and Mammino, L. (1987). 'Using the Analysis of Errors to Improve Students' Expression in Science', Zimbabwe Journal of Educational Research. Vol. 9, (1).

Assessment of Performance Unit. (1985). A Review of Monitoring in Mathematics: 1978 to 1982. London: HMSO.

Carpenter, T. P., Lindquist, M. M., Matthews, W. and Silver, E. A. (1983). 'Results of the Third NAEP Mathematics Assessment: Secondary School', Mathematics Teacher, 76, (9), 652-659. 
Erlwanger, S. H. (1973). 'Benny's Conception of Rules and Answers in Individually Prescribed Instruction Mathematics'. JCMB, Vol. 1, (2).

Eshun, B. A. (in press). The Pattern of Mathematical Achievement of Secondary School Students in Ghana', Journal of Science and Mathematics Education.

Garcia, G. E. and Pearson, P. D. (1994). 'Assessment and Diversity', In L. D. Hammond (Ed.). Review of Research Education. Washington D.C. 337391.

Ghana Ministry of Education (1987). Final Report of the Sub-Committee on Assessment at Basic Education Level. Accra: Ministry of Education

Ghana Ministry of Education (1993). Report of the Education Commission on Teacher Education. Accra: Ministry of Education.

Ghana Ministry of Education (1995). Primary Education Programme Report. Accra: Ministry of Education.

Gipps,C. V. (1994). Beyond Testing: Towards a Theory of Educational Assessment. London: The Falmer Press.

Host, R. and Bloomfield, B. (1975). Continuous Assessment in the CSE: Opinion and Practice. London: The Falmer Press.

Huerta-Marcias (1995). 'Alternative Assessment: Responses to Commonly Asked Questions', TESOL Journal Vol. 5, (1), 8-11.

Johnson, D. W. and Johnson, R. (1978). 'Cooperative, Competitive and Individualistic Learning', Journal of Research and Development in Education. Vol. 12, 3-15.

Lee, T. W. (1996). 'Mathematics Portfolios, NCTM Goals and Students' Perceptions: A Complex Analysis'. Dissertation Abstract International Vol. 57, (6).

LeMahieu, P. S. et al. (1995). 'Portfolios in Large Scale Assessment: Difficult but not Impossible', Educational Measurement Issues and Practice. Vol. 14, (3), 11-28.

Linn, R. L. and Burton, E. (1994). Performance Based Assessment: Implications of Task Specificity. Educational Measurement: Issues and Practice. Vol. 13, (1), 5-8.

Maqsud, M. and Khalique, C. M. (1991). 'Relationships of some SocioPersonal Factors to Mathematics Achievement of Secondary School and University Students in Bophuthaswana', Educational Studies in Mathematics. Vol. 22, (4), 377-390.

Newman, M. A. (1977). 'An Analysis of Sixth-Grade Children on Written Mathematical Tasks', Journal for Research in Mathematics Education. Vol. 13, (2), 136-144. 
The Effect of Alternative Assessment on the Attitudes and Achievement in Mathematics of Female Pre-Service Teachers in Ghana ESHUN, B. A. \& ABLEDU, G. K.

Randhawa, B. S. (1991). 'Three-Year Study of Saskatchewan High School Sophomores', Alberta Journal of Educational Research. Vol. 37, (3), 241-257.

Smolen, L. et al. (1995). 'Developing Student Self-Assessment Strategies', TESOL Journal. Vol. 5, (1), 22-27.

University of Cape Coast - Institute of Education, 1998). Chief Examiner's Report on the 1998 Three-Year Post Secondary Teacher Training College Part I Examination in Basic Mathematics, Cape Coast: University of Cape Coast, Institute of Education .

Viaskamp, D. C. (1995). 'Encouragement of Student Learning Through a Portfolio Process', Dissertation Abstract International. Vol. 55, (1).

Winzer, M. (1992). Educational Psychology in the Canadian Classroom. 2nd Edition. Ontario: Scarborough. 